\title{
Corrigendum
}

\section{The predominant role of recently discovered tetrahydropyrimidines for the osmoadaptation of halophilic eubacteria}

Jörg Severin, Axel Wohlfarth and Erwin A. Galinski

Journal of General Microbiology (1992), 138, 1629-1638

p. 1630, legend to Table 1:

In lines 5 and 6, the address for DSM should read Deutsche Sammlung von Mikroorganismen und Zellkulturen, Braunschweig, FRG.

p. 1630, Table 1:

In the first column, the subheading for the third group of organisms should read Proteobacteria ( $\gamma$-subclass).

p. 1632, column 2, line 12: for position 3 read position 5 .

p. 1634, column 1, line 2: for glycosylglycerin read glycosylglycerol.

p. 1635, column 2, line 16: for Firmacutes read Firmicutes.

The publishers apologize for these errors. 